\title{
Aortic thrombosis: the forgotten source of ischemic stroke. A case report and systematic review of the literature
}

\author{
Christian Basile, Costantino Mancusi, Paola Gargiulo, Pasquale Perrone Filardi, Cinzia Perrino, \\ Grazia Canciello, Maria Angela Losi, Giovanni Esposito
}

Department of Advanced Biomedical Science, Federico II University Hospital, Naples, Italy

\begin{abstract}
Ischemic stroke represents one of the most important health problems in industrialized countries, both for epidemiological and socio-economic impact. The presence of thrombi in the aorta is rare and its treatment has not been uniquely defined. Here we report the case of an 82-years-old man with aortic thrombosis and acute ischemic stroke.
\end{abstract}

Correspondence: Dr. Costantino Mancusi, Hypertension Research Center, Department of Advanced Biomedical Science University of Naples Federico II, Via Pansini 5, bld \#1, 80131 Naples, Italy. Tel. +39.081 .7462025 .

E- mail: costantino.mancusi@unina.it

Key words: aortic thrombosis; transesophageal echocardiography (TEE); aortic valve prosthesis; ischemic stroke; computed tomography (CT).

Contributions: $\mathrm{CB}, \mathrm{CM}$, conceived the paper and wrote the manuscript; PG, PPF, CP, CG, MAL, GE, contributed to the discussion and edited the manuscript. All the authors have read and approved the final version of the manuscript and agreed to be accountable for all aspects of the work.

Conflict of interest: The authors declare that they have no competing interests, and all authors confirm accuracy.

Received for publication: 18 September 2021.

Accepted for publication: 4 October 2021.

Publisher's note: All claims expressed in this article are solely those of the authors and do not necessarily represent those of their affiliated organizations, or those of the publisher, the editors and the reviewers. Any product that may be evaluated in this article or claim that may be made by its manufacturer is not guaranteed or endorsed by the publisher.

${ }^{\circ}$ Copyright: the Author(s), 2021

Licensee PAGEPress, Italy

Monaldi Archives for Chest Disease 2022; 92:2090

doi: 10.4081/monaldi.2021.2090

This article is distributed under the terms of the Creative Commons Attribution-NonCommercial International License (CC BY-NC 4.0) which permits any noncommercial use, distribution, and reproduction in any medium, provided the original author(s) and source are credited.

\section{Introduction}

Ischemic stroke represents one of the most important health problems in industrialized countries, both for epidemiological and socio-economic impact. Stroke is the first cause of permanent disability, the second of dementia, and the third of death, after cardiovascular disease and cancer [1]. We report the case of an 82-years-old man admitted to Coronary Care Unit (CCU) for lipothymia; extensive aortic thrombosis was diagnosed; during hospitalization patient suffered of an acute ischemic stroke. The patient was then treated with warfarin.

\section{Case Report}

An 82-year-old male was admitted to the CCU on suspicion of acute coronary syndrome with lipothymia. On admission, he was asymptomatic for chest pain and dyspnea with a blood pressure of 170/90 mmHg; electrocardiogram showed a sinus rhythm with abnormalities of ventricular repolarization in V3-V6 leads. Laboratory tests were positive for D-Dimer elevation, while ultra- sensitive troponin I was within the range $(35 \mathrm{pg} / \mathrm{mL})$ (Table 1). The patient was alert and oriented and reported different previous episodes of lipothymia and headache in the last three months. He had replacement of ascending aorta with a straight Galweave 32 prosthesis and aortic valve replacement with St. Jude trifecta 21 and CABG (Left internal thoracic artery on left anterior descending artery and great saphenous vein on 1st diagonal) about 6 years earlier for the occurrence of aortic stenosis with dilated aortic stenosis. Trans-thoracic echocardiography was of not good quality so that valve the patient performed a transesophageal echocardiogram, showing normal bioprosthetic aortic valve function and morphology, massive thrombosis in the thoracic aorta starting from the replaced aortic valve (Figure 1) and excluded the presence of thrombosis in the left atrial appendage. Based on the very high value of D-Dimer was decided to perform thoracic CT angiography to better characterize aortic thrombosis and to exclude also pulmonary embolization [2]. The thoracic CT scan confirms the presence of a massive thrombotic apposition starting from the ascending aorta that extends throughout the course of the aorta involving the main branches of division (carotid, subclavian and iliac bilaterally) (Figure 2). A few hours later, the patient appeared disoriented, with speech deficit and stretching of the buccal rim associated with right hemiparesis. Brain MRI was performed and confirmed the presence of ischemic stroke in the pontine anterior and median-paramedian left regions (Figure 3). Then, Warfarin therapy 
was started. During the following days, the patient showed progressive clinical improvement and reduction of D-Dimer (last $8.13 \mathrm{mg} / \mathrm{dL}$ ) for which the patient was transferred to the neurology department where he successfully continued the therapeutic and rehabilitative process up to discharge. At follow-up visit 3 months after the patients was stable, without any other CV events. Due to the presence of advanced chronic kidney disease no follow-up CT scan was performed.

Table 1. Blood analysis and therapy during hospitalization.

\begin{tabular}{|c|c|c|c|}
\hline Serum marker & Admission & Discharge & Reference values \\
\hline Sodium (mmol/L) & 135 & 140 & $135-145 \mathrm{mmol} / \mathrm{L}$ \\
\hline Potassium (mmol/L) & 4.9 & 5 & $3.5-5.1 \mathrm{mmol} / \mathrm{L}$ \\
\hline Creatinine (mg/L) & 1.82 & 1.75 & $0.72-1.25 \mathrm{mg} / \mathrm{dL}$ \\
\hline C-reactive protein (mg/L) & 18.70 & 69.60 & $0-5 \mathrm{mg} / \mathrm{L}$ \\
\hline Ultra-sensitive troponin I (pg/mL) & 35 & 15 & $0-35 \mathrm{pg} / \mathrm{mL}$ \\
\hline White Blood cell Count (x103/uL) & 11.91 & 10.76 & $4.8-10.8 \times 10^{3} / \mathrm{uL}$ \\
\hline Hemoglobin (g/dL) & 14.40 & 14.80 & $12.0-17.5 \mathrm{~g} / \mathrm{dL}$ \\
\hline Platelet count $\left(\mathrm{x} 10^{3} / \mathrm{uL}\right)$ & 187 & 409 & $130-400 \times 10^{3} / \mathrm{uL}$ \\
\hline D-Dimer (mg/L) & 21.23 & 8.13 & $0.1-0.6 \mathrm{mg} / \mathrm{L}$ \\
\hline Therapy & Admission & Discharge & Reference values \\
\hline $\begin{array}{l}\text { Bisoprolol } \\
\text { Ramipril atorvastatin } \\
\text { Pantoprazole }\end{array}$ & $\begin{array}{l}5 \mathrm{mg} \text { OD } \\
10 \mathrm{mg} \text { OD } \\
80 \mathrm{mg} \text { OD } \\
20 \mathrm{mg} \text { OD }\end{array}$ & $\begin{array}{l}\text { Suspended } \\
\text { Suspended } \\
\text { Continued } \\
\text { Continued }\end{array}$ & \\
\hline $\begin{array}{l}\text { Aspirin amlodipine } \\
\text { Clopidogrel warfarin }\end{array}$ & $\begin{array}{l}100 \mathrm{mg} \text { OD } \\
10 \mathrm{mg} \mathrm{OD}\end{array}$ & $\begin{array}{c}\text { Continued } \\
\text { Continued } 75 \mathrm{mg} \text { OD mg based on INR }\end{array}$ & INR range: $2.0-3.0$ \\
\hline
\end{tabular}

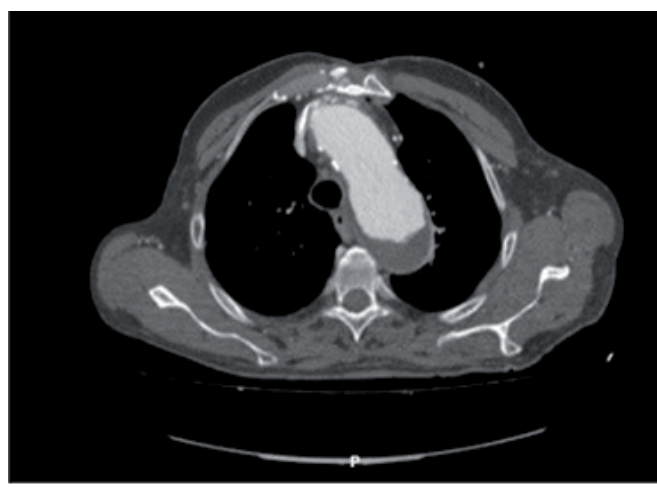

(a)

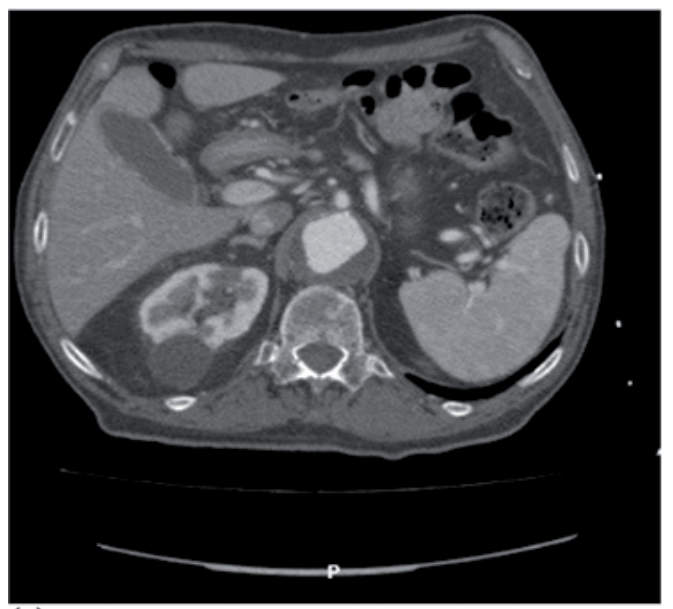

(c)

Clopidogrel warfarin

OD, omni die; BID, bis in die; INR, international normalized ratio.

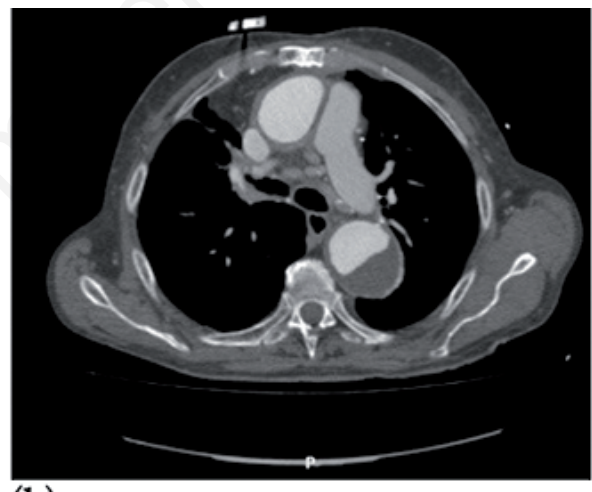

(b)

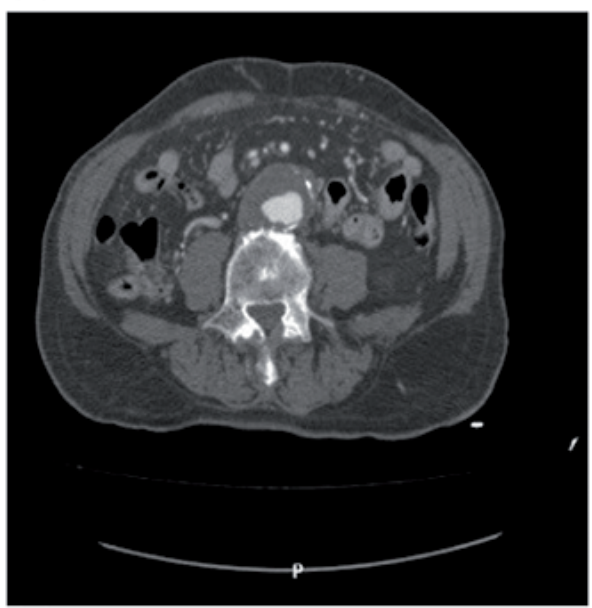

(d)
Figure 1. CT angiography of various segments of the aorta showing extensive thrombosis. a) Aortic arch; b) descending thoracic aorta; c) abdominal aorta; d) last part of the abdominal aorta just before the bifurcation. 


\section{Discussion}

Thrombosis of the ascending aorta is a rare and potentially lifethreatening condition and might complicated previous aortic valve replacement $[3,4]$. The cause of aortic thrombi is hard to define, as they can originate from blood disorders (protein $\mathrm{S}$ or protein $\mathrm{C}$ deficiency, anti-phospholipid antibody syndrome, etc.), tumors, aortitis, collagen disease, aortic aneurysms, intra-aortic atheroma, hormone therapy, steroid use, and atrial fibrillation [5]. Furthermore, the pathophysiological mechanism of isolated thrombi in an otherwise healthy aortic wall remains unclear. Primary endothelial disorder with hypercoagulability may be an explanation [6]. Aortic thrombi, as a variant of atherosclerosis in young

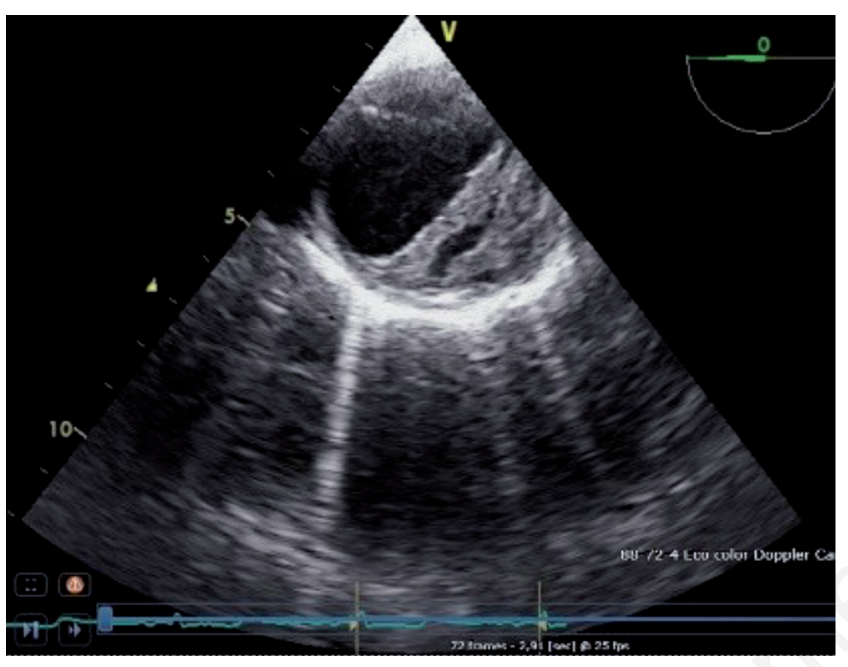

Figure 2. Thoracic aorta thrombosis at trans-esophageal examination.

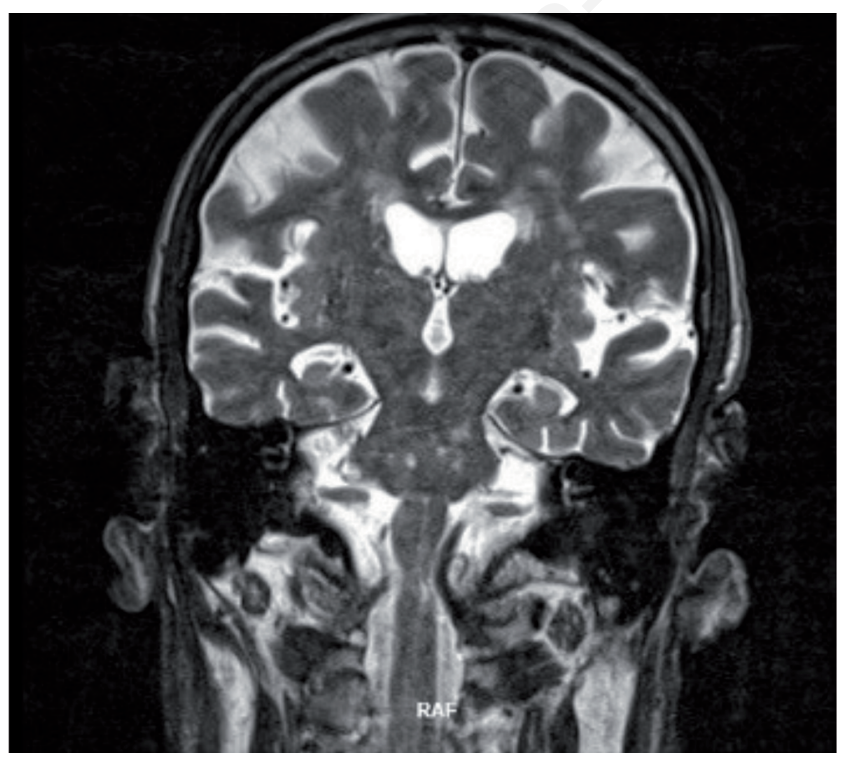

Figure 3. Ischemic stroke in the pontine anterior and medianparamedian left regions at the brain MRI. healthy patients, where localized clots are found even if no plaques are visible on CT scans, has also been considered. The aorta is frequently the site of atheromatous lesions and superimposed thrombotic formations; these lesions are now better-diagnosed due to transesophageal echocardiogram examination, which allows excellent visualization of the thoracic aorta. In addition to the heart chambers, a known source of emboli, the aorta must always be considered a potential embolic focus [7]. This evidence could motivate an in-depth transesophageal study of the aorta even in the presence of a recognized intracardiac embolic source. CT angiography is recommended as the first-choice examination not only for its high sensitivity and cost-effectiveness [8], but also because it may simultaneously indicate the presence of other aortic diseases, such as aortic aneurysm and aortic dissection. Furthermore, aortic arch is better visualized using CT scan compared to TEE. The presence of thrombi in the aorta is still considered rare [9] and its treatment has not been uniquely defined [10]. Symptoms are usually linked to embolism caused by shedding of the thrombus and include: loss of consciousness and dizziness (ischemic stroke), abdominal pain (splenic infarction), and lower limb pain (acute ischemia). Treatment could consist of the use of oral anticoagulants, antiplatelet agents, thrombolysis, or surgery. If the lesion is classified as a thrombus and is located in the descending or abdominal aorta, the use of anticoagulants and the implantation of an endovascular stent could be recommended. Anticoagulants include low-molecular-weight heparin, apixaban, and warfarin [11-13]. If a floating lesion in the ascending aorta is demonstrated by TTE and CT angiography thrombectomy on cardiopulmonary bypass could be recommended $[14,15]$.

The use of statins concomitantly with warfarin seems reasonable in patients with atheromatous aortic plaques complicated by thrombosis, and although the use of warfarin has not yet been evaluated in large randomized trials. The fear that anticoagulation may be harmful and initially favor the embolic manifestations does not seem to be confirmed, while the use of antiplatelet agents seems less effective and that of thrombolysis is still undetermined [1618]. Surgical removal is associated with high morbidity, especially in critical patients. The treatment strategy should consider individual parameters such as the patient's age, hemodynamic stability and comorbidities: for young and healthy patients, surgery may be a good option. Thrombus tendency should be also considered. Lifetime anticoagulation seems rational as new thrombi may present as a life-threatening situation. Duration of anticoagulation should therefore be based upon patient-specific bleeding and thrombotic risks. Our patient was elderly and frail with a high surgical risk and hemodynamic stability. For these reasons, without clear evidence in the literature, it was preferred to postpone surgical therapy and proceed with anticoagulation alone [19].

\section{References}

1. Majersik JJ, Woo D. The enormous financial impact of stroke disability. Neurology 2020;94:377- 8.

2. Erbel R, Aboyans V, Boileau C, et al. 2014 ESC Guidelines on the diagnosis and treatment of aortic diseases: Document covering acute and chronic aortic diseases of the thoracic and abdominal aorta of the adult. The Task Force for the Diagnosis and Treatment of Aortic Diseases of the European. Eur Heart J 2014;35:2873-926.

3. Sachdev S, Bardia N, Nguyen L, Omar B. Bioprosthetic valve thrombosis. Cardiol Res 2018;9:335-42 
4. Pradegan N, Basso C, Della Barbera M, et al. Cardiac arrest due to acute massive aortic root thrombosis after pericardial bioprosthetic aortic valve replacement. Cardiovasc Pathol 2019;41:8-10.

5. Yamase Y, Kuwabara F, Watanabe K, et al. A case of floating thrombus in the ascending aorta that caused recurrent peripheral arterial embolic events. J Cardiol Cases 2015;12:57-60.

6. Bowdish ME, Weaver FA, Liebman HA, et al. Anticoagulation is an effective treatment for aortic mural thrombi. J Vasc Surg 2002;36:713-9.

7. Reber PU, Patel AG, Stauffer E, et al. Mural aortic thrombi: An important cause of peripheral embolization. J Vasc Surg 1999;30:1084-9.

8. Barry N, Tsui J, Dick J, et al. Aortic tumor presenting as acute lower limb ischemia. Circulation 2011;123:1785-7.

9. Stoevesandt D, Klempt C, Scheubel R, et al. Embolic events caused by aortic thrombi: an underestimated entity? J Thromb Thrombolysis 2013;35:223-7.

10. Yang $\mathrm{P}, \mathrm{Li} \mathrm{Y}$, Huang $\mathrm{Y}$, et al. A giant floating thrombus in the ascending aorta: a case report. BMC Surg 2020 9;20:321.

11. Dhillon P, Murdoch D, Jayasinghe R, Niranjan S. A case of mobile aortic arch thrombus with systemic embolisation, a management dilemma. Heart Lung Circ 2014;23:e88-91.

12. Houmsse M, McDavid A, Kilic A. Large de novo ascending aortic thrombus successfully treated with anticoagulants. J Cardiovasc Thorac Res 2018;10:113-4.
13. Scott DJ, White JM, Arthurs ZM. Endovascular management of a mobile thoracic aortic thrombus following recurrent distal thromboembolism: a case report and literature review. Vasc Endovascular Surg 2014;48:246-50.

14. de Maat GE, Vigano G, Mariani MA, Natour E. Catching a floating thrombus; a case report on the treatment of a large thrombus in the ascending aorta. J Cardiothorac Surg 2017;12:34.

15. Campanile A, Sardone M, Pasquino S, et al. Surgical management of a free-floating thrombus in the ascending aorta. Asian Cardiovasc Thorac Ann 2019;27:221-3.

16. Wang B, Ma D, Cao D, Man X. Huge thrombus in the ascending aorta: a case report and literature review. J Cardiothorac Surg 2019;14:157.

17. Tunick PA, Kronzon I. Atheromas of the thoracic aorta: clinical and therapeutic update. J Am Coll Cardiol 2000;35:545-54.

18. Laperche T, Laurian C, Roudaut R, Steg PG. Mobile thromboses of the aortic arch without aortic debris. A transesophageal echocardiographic finding associated with unexplained arterial embolism. The Filiale Echocardiographie de la Société Française de Cardiologie. Circulation 1997;96:288-94.

19. Reyes Valdivia A, Duque Santos A, Garnica Ureña M, et al. anticoagulation alone for aortic segment treatment in symptomatic primary aortic mural thrombus patients. Ann Vasc Surg 2017;43:121-6. 